\title{
World Population Growth and Some Implications*
}

\author{
HALVOR GILLE†
}

Brit. med. F., 1965, 2, 1302-1304

The British Medical Association is to be congratulated on having devoted a special session of its annual meeting to one of the most serious social problems confronting the world to-day-the rapid growth of the population, particularly in the newly emerging countries.

\section{Unprecedented Increase}

The present world population of about 3,400 million is increasing by 70 million a year. At this rate the population will be doubled in barely thirty-five years. Never before has mankind experienced such a rapid growth. In the Middle Ages the increase was on the whole very small, amounting merely to a doubling of the population over a time span of about one thousand years. During the nineteenth century the rate of growth was slowly increasing, amounting on an average to $0.5 \%$ a year. Soon after the second world war the rate began to climb rapidly, and to-day it has reached $2.1 \%$.

In the less-developed countries, mainly in Africa, Asia, and Latin America, the population growth is almost everywhere substantially higher than in the economically developed countries in the West. In Latin America the increase is at the unprecedented rate of almost $3 \%$ a year and that of South-east Asia is nearly as high $(2.7 \%)$. In these regions a number of countries have a rate of growth around $3.5 \%$, which means that their population tends to double in twenty years or less. In contrast, the European countries have a very modest rate of growth - on an average less than $1 \%$ a year.

\section{Three Important Factors}

This recent rapid increase is mainly due to a spectacular decline in mortality experienced in the less-developed countries. Improvements in their health conditions and the application of effective methods of preventing and curing diseases have brought about a revolution in mortality and morbidity. In some of the countries in Asia, Latin America, and Africa the life expectancy for a newly born child has increased in recent years by about one year per annum. The similar demographic transition in the now developed countries in the West was far less dramatic: for example, in the part of the world I come from, Scandinavia, life expectancy in the nineteenth century increased only by about two years per decade.

Another important feature of the present demographic situat on is the general stability in the level of fertility, particularly in the less-developed countries. The birth rate in Latin America, Africa, and Asia is about twice as high as that in the rest of the world. In most countries the birth rates are within the range of 40 to 50 per 1,000 population-in some areas, especially in Africa, birth rates of 55 to 60 are recorded. In North America and Europe, including the Soviet Union, the birth rate is below 25 per 1,000 , and in some countries even lower than 15 .

So far there has been little indication of any major decline in the birth rate in the less-developed regions. Apart from Japan, where a spectacular fall in fertility has taken place since the last war, and a few isolated cases such as Puerto Rico, Taiwan, and Malaya, no major decline seems to be under way anywhere as yet. Actually, in a few instances a rise in the birth rates in recent years may be cited.

\section{A Heavy Burden}

The spectacular decline in mortality and the absence of any general decline in fertility have resulted not only in a rapid rise in world population but also in throwing a heavy burden on the developing countries, a large proportion of whose inhabitants are in the young and unproductive age groups. In most of these countries around 40 to $45 \%$ of the people are under 15 years of age, and in others even half are in that age group, due to a very high level of fertility. The large number of children is a serious handicap in improving the economic and social conditions. While in this country one dependent person is supported on an average by three persons in the productive age groups, the ratio between these two population groups in the developing countries is two to three.

Areas in which the population growth is rapid have to spend an increasing proportion of their resources on food, clothing, housing, and other necessities merely to maintain the present low levels of living, leaving less for development purposes. In India the numbers to be provided with these necessities increase by one million every single month, and in China by even more than that.

The difficulties of maintaining an increase in agricultural productivity to exceed the growth in population are being increasingly felt. It is estimated by the Food and Agriculture Organization that $15-20 \%$ of the people in developing countries are undernourished and that the large majority are malnourished. In Asia and the Far East, where more than half of the world population is concentrated, the agricultural production per head is still below the low pre-war level ; in the last five years population growth has outstripped food production. In Latin America the nutritional conditions are better but the population has increased by a rate almost twice that of the rise in food production. In contrast, the industrialized countries in North America and Western Europe had raised their food production far ahead of population growth, thus widening the gap further between the rich and the poor regions of the world.

\section{Food Production}

There are, no doubt, large unexploited resources and considerable potentialities for increasing food production, but the question is to what extent the developing countries will be able to provide soon enough the huge investments required, and to bring about the necessary social changes, if full use is to be made of the land resources and the large under-employed labour force. The Food and Agriculture Organization has estimated that the food supply has to be stepped up by $4 \%$ a year in order to provide enough for the increasing population, and, at the same time, to improve the quantity and the quality of the diet so that acceptable levels may be reached in about 15

\footnotetext{
* Contribution to a world population symposium delivered at the Annual Meering of the British Medical Association, Swansea, July 1965. + Chief, Office of Social Affairs, European Office of the United Natione Geneva.
} 
years. This rate of agricultural development has not been reached so far in any of the developing regions of the world, nor has it been experienced in the developed countries over comparable periods. Merely to keep abreast of the high rate of population growth, if it were to continue, leaving the present level of nutrition unchanged, would require an increase in productivity at least as high as that accomplished in the West in recent decades. Whether this is feasible remains to be seen, but without this increase the developing countries would become more and more dependent on the industrialized world for survival.

\section{Problem of Education}

Another important field for development is that of education. In spite of vigorous efforts to provide schooling for an increasing population there are still more illiterate young people and adults in many developing countries, as for example India and Pakistan, than ten or fifteen years ago. One of the major social goals of most of these countries is that of providing facilities for primary education for all children in about fifteen years' time. In South-east Asia this would require an increase in school-rooms, teachers, books, etc., of about 300\%-that is, more than four times the expected increase in the adult working population. If a rapid reduction in fertility was brought about, so that fertility would be halved in fifteen years, the goal would not be so difficult to reach, since the number of children of school age would be no higher than it is to-day. In many other fields of economic and social development, such as housing, public health, and employment, the situation is the same: a slowing down of the birth rate and population growth would facilitate the task of improving living conditions.

Apart from the problem of economic development and social welfare of a country as a whole, the health and the well-being of individual families, the mothers, and the children are of great concern. This aspect of the population problem is, of course, of special interest to the medical profession. Many childbirths, and the care of a large family, are an immense strain on a woman, and may endanger her health and even her life. About two-thirds of all deaths among women in the reproductive ages in India are from causes connected with pregnancy and childb rth. Everybody seems to agree that family limitation is an important and desirable measure for the protection of the health and welfare of mothers and children.

\section{Room for Improvement}

The most serious aspect of the demographic situation is the prospect of continuing and even higher rates of population growth in the near future. In spite of recent reduction in mortality in many developing countries, there is room for further improvement. In some African countries the death rate is three times or more than that in industrialized countries: at least one-quarter of all live-born children die before they are 1 year old. Recent achievements in public health in many parts of the world have. clearly shown what a determined governmental policy can accomplish, and there is no doubt that vigorous attempts will be made in other areas to improve health conditions. The current high rate of population growth may be stepped up further. It will, however, not continue to accelerate. The fall in mortality will tend to slow down as lower levels are approached, and the impact upon the rate of population growth will be more limited.

The only factor which could bring about a check in population growth and change the present unfavourable age structure in the developing countries is a reduction in fertility. It must be recognized, however, that such a change is not easily brought about. A decline in fertility will affect the rate of population growth and the age structure to any extent only in the long run. A decline brought about by an active programme would have only a limited impact in the first ten to fifteen years, during which period any reduction in the birth rate may be counteracted by expected further declines in the death rate. The same is the case with the effects upon the age structure, where a major shift between the active and inactive population groups will be accomplished only after about fifteen years, when the smaller birth cohorts begin entering the reproductive ages.

Another problem is that the present high-family-size norms prevailing in developing countries are not easily changed. Basic elements of human behaviour, such as religious convictions, family organization, economic needs, and cultural traditions, are involved. Resistance to change is considerable in many of those countries where $80 \%$ or more of the population are living in rural areas in isolation, with little hope of improvement and the bare minimum of means of subsistence. Some of these countries have found it easier to build huge steel plants and atomic reactors than to change the outlook of the people towards matters of procreation and family-building.

\section{Family Planning}

A major problem in bringing about a decline of fertility in those circumstances has been to find suitable means and devices for family planning which can be applied on a large scale and which are acceptable to most people. It has been proved over and over again that the methods used in the West are not generally and easily applicable in the less-developed countries. A major breakthrough, however, seems to have been made with the successful application of intrauterine devices in several countries. These devices have the great advantage of being not only fairly effective in controlling fertility but at the same time inexpensive, safe, and generally acceptable. They also have the great advantage of not requiring any follow-up work, are reversible, and can probably be used as long as desired. This is, of course, not the ideal method (about $15-20 \%$ of the women cannot use it for various reasons); research must go on and will go on, but for the first time we have a method which can be of great help to developing countries and which has been widely accepted; in Taiwan $80 \%$ of the women offered various contraceptives in the cafeteria-style choose the intrauterine device.

In recent years considerable evidence has been received from various developing societies that there is a widespread and increasing desire to limit fertility. However, while suitable methods may soon be available in many places, there will still be a long way to go before they are accepted by most of those concerned. It will be a major, and difficult, task to organize services, reach the people through educational means, and translate the changed outlook into individual acts. Furthermore, the existing norms for family size in many of the countries may still be well above what would be needed to stabilize the populat on or maintain a rate of growth most beneficial for economic development.

\section{Standards of Living}

The present rate of population growth is recognized by many developing countries as a serious handicap in their efforts to improve standards of living. It may not be correct to say that the current high rates of population growth would lead to disaster in the very near future. Some improvements in economic and social conditions are taking place in spite of the present high rates of population growth. But the important fact is that the present rate of improvement in living conditions is far short of the aspirations of the people of these countries for a better life for themselves and their children, and is also 
far short of the economic growth generally taking place in the West. Frustrations in the developing countries and the widening gap between living conditions in these areas and those in the industrialized world could become a menace to human well-being and world peace. It is becoming more and more evident that to tackle the problems of economic and social development population trends must be taken into account. A concerted action is required to deal with the population question at the same time as measures are taken to step up economic growth and social progress-otherwise much of the national and international assistance given, and money invested, will be wasted. When, last winter, the International Bank for Reconstruction and Development was requested by the Government of India to evaluate the economic situation and consider providing a major loan for the implementation of the next Five Year Plan several experts on population and family planning were included in the Mission sent by the bank to examine on the spot the problems of and potentialities for economic development. It is now evident that population questions in the developing countries are of keen international concern and a major challenge to the international organizations.

These organizations have been slow to recognize the importance of population problems, but they can proceed only as rapidly as the great majority of member Governments permit. Nevertheless, the United Nations has for a long time been in a position to give assistance, in particular to research and training. It has also, to a limited extent, been able to assist governments asking for advice on measures to curb population growth: a mest important venture in this respect was the advisory mission on family planning which the United Nations sent to India a few months ago. Recently the United Nations has adopted a long-range programme which gives considerable attention to the needs of developing countries for assistance on problems of population policies. In the important debate proceeding in the Economic and Social Council in Geneva impatience is being expressed with the slow economic and social development in the low-income countries, and the problems of population growth are being given close attention.

\section{Change in Policy}

A major change in policy took place in the World Health Organization some weeks ago, when the Health Assembly, after 13 years of inaction, adopted a resolution approving in principle that advisory services be given on medical and public health aspects of family planning, provided that such technical advice did not involve operational activities. It remains to be seen how soon and in what way the organization will give assistance when requested. Also the Food and Agriculture Organization and Unesco are becoming increasingly concerned with the problems of food supplies and education facilities affected by rapid growth in population.

The international organizations have, unfortunately, very limited resources and therefore can make only a modest contribution towards tackling the serious population problems confronting the world. However, the recent change in their attitude is of great moral and psychological importance. It is understood, of course, that the international agencies will never advocate any particular policies, but will merely, at the request of governments, assist them in their endeavours to cope with these problems in the way they desire.

\section{Conclusion}

Side by side with the work of the international organizations, several governments in the West, including Her Majesty's Government, are ready to make a major contribution towards assisting developing countries. In addition, the professions concerned with the social problems involved, in particular the medical profession, have an important part to play. By making available the knowledge and experience you doctors have gained, and by guiding your colleagues in developing countries, you can make a major contribution towards solving an urgent problem in these countries and the world as a whole. Your support and co-operation will contribute immensely to raise the prestige and effectiveness of the family-planning programme.

Note.-The views expressed in the above paper are the author's and not necessarily those of the United Nations.

\title{
Society for Social Medicine
}

\author{
[From a Special Correspondent]
}

The ninth annual meeting of the Society for Social Medicine was held on 21-23 September in Sheffiell. The meeting opened with a session on respiratory disease and the effects of atmospheric pollution. Dr. J. E. LunN (Sheffield) described a study of 322 children aged $10-11$ years, 177 living in areas of low pollution and 145 from areas with two or three times the level of smoke and sulphur dioxide. The children from the latter areas had a higher incidence of miduleear disease and bronchitis and performed less well in ventilatory function tests, in particular the peak expiratory flow rate. There were no differences in the incidence of upper respiratory tract infections. The social class distribution of the children in the two groups of areas was very similar, but factors such as bed-sharing and room-sharing indicated poorer home conditions in the areas with higher atmospheric pollution.

Drs. P. J. Lawther and J. W. B. Douglas (London) gave an account of the respiratory infections in a sample of 5,000 children born in March 1946. They also found a higher incidence of lower respiratory infections in polluted areas, but little difference in upper respiratory tract infections. Dr. W. FIELD (Gloucester) presented a preliminary report of a necropsy study in which she is correlating the Reid index for mucous gland hypertrophy and acinar counts with respiratory symptoms, smoking habits, and area of residence.

\section{Anencephaly and Backward Children}

In a session on the newborn, Drs. R. G. RECORD and I. M. LECK (Birmingham) drew attention to the increase in incidence of summer-born children with anencephalus in recent years, which had distorted the previously described seasonal variation. $\mathrm{Dr}$. E. A. SMith (Edinburgh) illustrated the potentialities of record linkage. Using the Registrar-General for Scotland's records, he showed that it was possible to identify families in which more than one anencephalic stillbirth had occurred. He found that familial cases did not differ in any obvious way from other anencephalics. Dr. D. J. P. BARKER (Birmingham) reported a study of backward children. These children are known to include an undue proportion with low birth weight. Dr. Barker produced evidence to show that this may be due to slow intrauterine growth as well as to prematurity.

Three papers then followed which emphasized two of the more common problems of epidemiology : the drawing of logical inferences from differences between groups and observer variation. Drs. D. C. PAtTison and M. J. Gardner (London) described a further study of arteriosclerotic heart disease in London bus drivers and conductors. Their aim was to elucidate the extent to which the difference between these two groups could be ascribed to selection, either "self" or “imposed." Drs. J. A. H. Waterhouse, Paula Cook, P. Gregory, and R. W. 